\title{
Screening for Partial Physiological Resistance to White Mold in Dry Bean Using Excised Stems
}

\author{
P.N. Miklas', K.F. Grafton ${ }^{2}$, and B.D. Nelson ${ }^{3}$ \\ North Dakota State University, Fargo, ND 58105-5051 \\ Additional index words. Sclerotinia sclerotiorum Phaseolus vulgaris, avoidance, disease resistance, lesion length, \\ laboratory screening method
}

\begin{abstract}
A laboratory procedure was tested to determine whether excised stems would allow a reliable indication of partial physiological resistance (PPR) to white mold [Sclerotinia sclerotiorum (Lib.) deBary] in dry bean (Phaseolus vulgaris L.). Excised stems from 11- and 28-day-old plants were inoculated with growing mycelium of $S$. sclerotiorum, incubated for 4 to 7 days (11- and 28-day assays, respectively), then assayed for lesion length (LL). A total of 15 bean genotypes were screened for PPR, as indicated by LL. Significant $(P<0.05)$ differences among LL means of smalland medium-seeded bean genotypes were detected in the 28-day assay, whereas only LL means among medium-seeded genotypes. differed significantly $(P<0.05)$ in the n-day assay. 'Bunsi', 'C-20', 'Sierra', 'Topaz', and snap bean breeding lines NY 5262, NY 5394, and NY 5403 had the highest PPR and 'Upland', D76125, and 'UI-114' the lowest. The results from both assays were repeatable. A moderately high correlation $(r=0.68, P<0.02)$ was observed between PPR and field resistance. The 28-day assay has potential for evaluating dry bean germplasm for PPR to white mold disease caused by S. sclerotiorum. A 28 -day assay also was used to measure virulence of 18 isolates of $S$. sclerotiorum. The 18 isolates did not differ $(P<0.05)$ for virulence when measured by $L$. The lack of any genotype $x$ isolate interaction for $L L$ indicated lack of host-pathogen specificity.
\end{abstract}

White mold is a major concern to dry bean growers, processors, and breeders because it reduces seed yields (Steadman, 1979). Laboratory, mist-chamber, and field-screening tests have shown that some bean genotypes have partial resistance to white mold (Fuller et al., 1984; Hunter et al., 1981; Miklas et al., 1992; Schwartz et al., 1987). Laboratory methods screen solely for PPR. In addition to screening for physiological resistance, mist-chamber tests (Hunter et al., 1981) screen epidermal tissue for resistance to pathogen penetration. Partial resistance, when evaluated in field trials, is conditioned by physiological and avoidance mechanisms (Schwartz et al., 1987).

Increasing PPR in dry bean can help reduce white mold incidence and severity (Dickson et al., 1982; Lyons et al., 1987). Simplicity, reliability, and obtaining a measure of PPR that correlates well with field resistance are essential to any successful screening procedure: The limited-term inoculation (LTI) mist-chamber method developed by Hunter et al. (1981) is the procedure used most frequently to screen bean for PPR to white mold. The results, however, can be difficult to repeat. That LTI can be a nondestructive test is an advantage; therefore, individual plants with superior PPR can be selected. Miklas et al. (1992) reported that a laboratory screening technique using callus culture was reliable.

Few studies on white mold have used laboratory or mistchamber screening methods to compare PPR directly to field resistance. Cline and Jacobsen (1983) observed that PPR of soybean [Glycine max (L.) Merr.], determined by LTI (Hunter

Received for publication 10 Apr. 1991. Accepted for publication 9 Oct. 1991. Contribution of the North Dakota State Agr. Expt. Sta. Paper no. 1950. Partial fulfillment of P. N.M.'s PhD dissertation. Research was supported in part by grants from The Quaker Oats Co. M.H. Dickson, H.F. Schwartz, M.A. Brick, and D. P Coyne contributed bean genotypes. J.R. Steadman contribute disolates of S. sclerotionon. J .R. Venette reviewed the manuscript. W.L. Albus and J. Vander Wal provided technical assistance. The cost of publishing this paper was defrayed in part by the payment of page charges. Under postal regulations, this paper therefore must be hereby marked advertisement solely to indicate this fact.

'Currently Research Geneticist. Current address: USDA, ARS, Tropical Agricultural Research Station, P.O. Box 70, Mayaguez, Puerto Rico 00681.

${ }^{2}$ Associate Professor, Dept. of Crop and Weed Sciences.

${ }^{3}$ Associate Professor, Dept. of Plant Pathology. et al., 1981), was similar to field resistance; however, no statistical comparisons were made. Chun et al. (1987) detected only one significant correlation of many calculated between PPR, determined by excised-stem assays, and field resistance. Fuller et al. (1984), while conducting an inheritance study, observed a significant correlation between PPR, determined in the greenhouse, and field resistance.

Further research was needed in bean to identify a reliable laboratory screening method to measure PPR that compares well with field resistance. The LL assay of excised stems developed by Chun et al. (1987) might be such a method. The objectives of our study were to i) examine the virulence of various $S$. sclerotiorum isolates with a LL assay of excised stems; ii) evaluate the reliability of the LL assays of excised stems for detecting PPR in dry bean; and iii) determine if PPR, as measured by LL assays of excised stems, would be correlated with field resistance.

\section{Materials and Methods}

Isolates. Isolates used in this study were obtained from J.R. Steadman, Univ. of Nebraska, and B.D. Nelson, North Dakota State Univ. These isolates were comprised of sclerotia taken from potato dextrose agar culture or obtained from infected greenhouse-grown plants. To maintain isolates, sclerotia were collected periodically from potato dextrose agar culture or infected greenhouse-grown plants.

Inoculum preparation. Sclerotia were hydrated for $20 \mathrm{~min}$ in cold tap water, surface sterilized for $30 \mathrm{sec}$ in a 1:1 (v/v) solution of commercial bleach and $950 \mathrm{ml}$ aqueous ethanol/liter and air dried. A single sclerotium of an individual isolate was placed in the center of a $15 \times 100-\mathrm{mm}$ petri plate containing $20 \mathrm{ml}$ of potato dextrose agar amended with $150 \mathrm{mg}$ streptomycin/liter. Plates were incubated for 5 to 7 days at $18 \mathrm{C}$ and a 14-h light period was provided by two $20-\mathrm{W}$ cool-white fluorescent lights $\left(39 \mu \mathrm{mol} \cdot \mathrm{m}^{-2} \cdot \mathrm{s}^{-1}\right)$. Three $20 \times 5-\mathrm{mm}$ rectangular strips of agar, with mycelium, were transferred to a tissue-

Abbreviations: DII, disease incidence index; LL, lesion length; PPR, partial physiological resistance 
paper medium. Preparation, incubation, and use of the tissuepaper inoculum followed the procedures of Nelson (1985).

Excised stern preparation. Three seeds of a bean genotype were sown per $4.5 \times 5.5 \times 3.5-\mathrm{cm}$ container and 1.5-liter $(15-$ $\mathrm{cm}$ diameter) pot for plants grown 11 and 28 days, respectively. Each container and pot was thinned to one plant. An artificial soil medium was used for potting plants (Sunshine Mix; Fison Hort., Vancouver, B.C.). No fertilizer was added. The greenhouse was maintained at $\approx 26 \mathrm{C}$ and a 14 - to 16 -h photoperiod, provided by natural and/or high pressure sodium light (1300 $\left.\mu \mathrm{mol} \cdot \mathrm{m}^{-2} \cdot \mathrm{s}^{-1}\right)$.

Stems of plants were cut at the soil level, and all lateral branches and leaves were trimmed from the main stem. When 11-day-old plants were used, only cotyledons were removed. Before they were inoculated, stems were cut immediately below the primary leaf node and the sixth node in all cases except for NY 5403, for 11- and 28-day-old plants, respectively. Length and weight of each excised stem were recorded for all experimental repetitions of the 11-day assay and across isolates and four replicates in repetition 2 of the 28-day assay.

Inoculation. Excised stems were inoculated within $1 \mathrm{~h}$ of collection. To maintain humidity at the stem apex, we cut the stems below the appropriate node just before inoculation. The newly cut apex was inoculated by wrapping it with a $5 \times 3$ $\mathrm{mm}$ piece of tissue paper inoculum (Nelson, 1985) that contained growing mycelium. Inoculated stems were laid flat on $14 \times 18 \times 2-\mathrm{cm}$ trays containing 1 liter of vermiculite moistened with $600 \mathrm{ml}$ of distilled water and enclosed with plastic film to maintain humidity. Trays of inoculated stems were incubated on laboratory benches or in growth chambers in darkness at $\approx: 20 \mathrm{C}$ for 4 or 7 days, when excised stems from 11- or 28-day-old plants were tested, respectively. LL was measured in millimeters from the inoculated apex to the boundary of the water-soaked and normal tissue. The LL of excised stems from 11- and 28-day-old plants (11- and 28-day assays, respectively), were used to estimate PPR of bean genotypes and virulence of S. scleroriorum isolates. Stem weight divided by stem length $\left(\mathrm{mg} \cdot \mathrm{mm}^{-1}\right)$, as an estimate. of stem size, was investigated for covariate adjustment of LL means, because stem size varied among genotypes. An estimate of infected stem volume, obtained from: (stem weight/stem length) $\times$ LL, also was investigated for ability to measure PPR of dry bean stem tissue.

Three separate assays were conducted: 1) A 28-day assay of a susceptible control ('UI-114') and a partially resistant control ('Bunsi') (Schwartz et al., 1987) was used to examine virulence of 18 isolates of $S$. sclerotiorum (Table 1). This experiment was conducted twice. Only sclerotia obtained from infected greenhouse plants were used to produce inoculum in Repetition 2. 2) A 28-day assay was used to evaluate PPR of 12 bean genotypes (Table 2). Three isolates, ND16, ND26, and ND30 (Table 1 ), were included to examine host-pathogen specificity. This assay was run twice. 3) An 1 1-day assay was used to evaluate PPR of 15 bean genotypes (Table 2). Only one isolate, ND26, was used. This assay was conducted five times.

For each assay, the experiment design was a randomized complete block with five to 17 replications. A single genotype represented a treatment when only one isolate was used; when multiple isolates were used in an experiment, treatments were represented by a factorial arrangement of genotype $\times$ isolate. A single excised stem represented an experimental unit.

Field trials. Three field trials were conducted at the Oakes Irrigation Field Trials (Garrison Conservancy District, U.S. Reclamation Serv.) to determine field resistance of 13 bean geno- types. Trial 1, consisting of single-row plots with one common border, was planted 15 May 1988. Trial 2, consisting of singlerow plots with two common borders, and Trial 3, consisting of three-row plots, were planted 25 May 1989. Trial 3 was included to monitor the expression of disease avoidance. With each field trial, the experiment design was a randomized complete block, with genotypes replicated four times in Trial 1 and three times in Trials 2 and 3. Row spacing was $0.76 \mathrm{~m}$, and row lengths were 4.6 and $4.2 \mathrm{~m}$ in 1988 and 1989 , respectively. Seeding rates were 180,000 and 210,000 seeds/ha for mediumand small-seeded genotypes, respectively. To encourage natural infection and reduce avoidance, sclerotia obtained from commercial bean processing plants were incorporated into the soil during Fall 1988, and windbreaks, overhead irrigations, and border rows of the susceptible check 'UI-114' were used. $\mathrm{Nu}$ merous overhead irrigations were used to -supplement natural precipitation to maintain soil wetness during blossoming.

Bean genotypes were evaluated for field resistance on 9 Aug. each year, using a DII that evaluated disease incidence and severity. DII = visual score + number of infected branches + number of infected pods. The idea of the visual score ( 0 to 5 ) is much like that used by Coyne et al. (1977), but those authors used a scale of 1 to 6 , taking into consideration severity and incidence. Our visual score ( 0 to 5$)$ was taken from the middle row of a plot and represented a combination of incidence and severity with $0=$ no disease present; $1=10 \%$ to $20 \%$ of plants infected and/or $<10 \%$ to $25 \%$ of canopy diseased; $2=$ $20 \%$ to $40 \%$ of plants infected and/or $10 \%$ to $25 \%$ of canopy diseased; $3=40 \%$ to $60 \%$ of plants infected and/or $25 \%$ to $50 \%$ of canopy diseased; $4=60 \%$ to $80 \%$ plants infected and/ or $50 \%$ to $90 \%$ of canopy diseased; and $5=$ more than $80 \%$ of plants infected and/or $>90 \%$ of the canopy diseased. Percentage of canopy diseased is a criterion similar to the percentage of plant tissue infected (Coyne et al., 1977; Schwartz et al., 1987). The number of infected branches and pods, counted on 10 individual plants selected randomly from the middle row of a plot, was used as a plant average. If an individual plant selected was dead because of infection by S. sclerotiorum, it was counted as 10 infected branches and 10 infected pods.

Data analysis. All statistical analyses were performed using general linear models and correlation programs of Statistical Analysis Systems (SAS Institute, Cary, N.C.). Since residual plot analyses indicated normal distribution of error, no transformation of data was required. Means were adjusted for missing data using least squares. Data were combined across assay repetitions or field trials because errors of each repetition or trial were homogeneous. A weighted analysis was used with combined data whenever unequal treatments, replications, or missing data occurred (Cochran and Cox, 1957). Assay repetitions and field trials were considered random effects, and bean genotypes and isolates of $S$. sclerotiorum were considered fixed effects for all analyses. When an interaction mean square was nonsignificant $(P>0.05)$, it was combined with the pooled error mean square to test the main effect (Cochran and Cox, 1957). Differences among means were tested using Fisher's least significant difference (LSD) if the F ratio was significant. Differences among means from the weighted analyses were determined with either LSD formulated according to Gomes and Guimaraes (1957) for unbalanced designs or based on the smallest N. Covariance analysis was conducted to investigate stem weight divided by stem length as a covariate adjustment of bean genotype LL means. Correlations between the combined DII means and LL or infected stem volume means of separate rep- 
Table 1. Lesion length means ${ }^{z}$ from a 28 -day assay of two bean genotypes inoculated with 18 isolates of Sclerotinia sclerotionum.

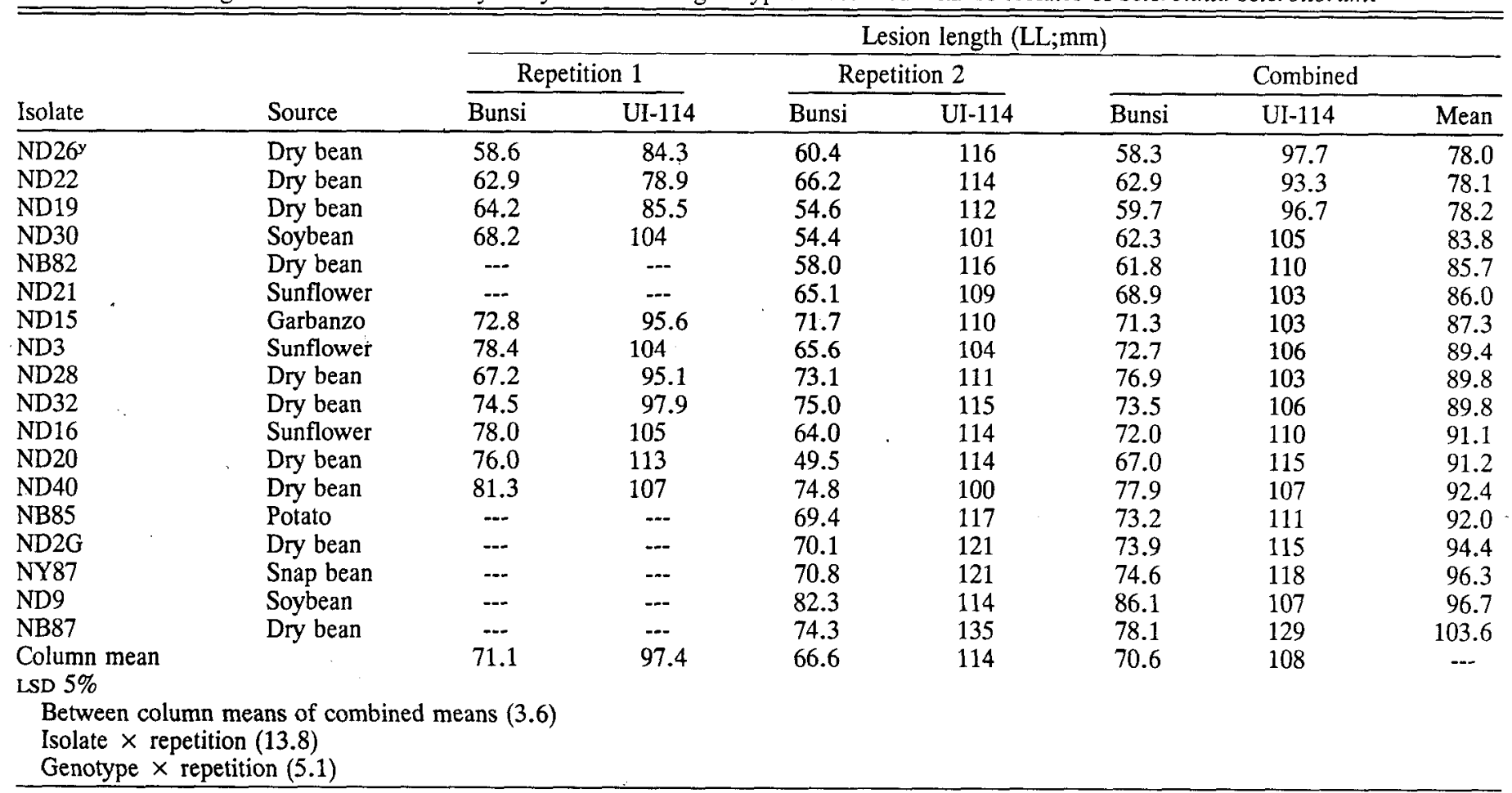

${ }^{2}$ Means were based on 17 and nine replicates for Repetitions 1 and 2, respectively.

${ }^{y} \mathrm{NB}, \mathrm{NY}$, and ND represent state of origin or isolates.

Table 2. Description of the 15 bean genotypes evaluated for partial physiological and field resistance to white mold disease in this study.

\begin{tabular}{|c|c|c|c|c|}
\hline Genotypes & $\begin{array}{c}\text { Market } \\
\text { class }\end{array}$ & $\begin{array}{l}\text { Growth } \\
\text { habit }^{z}\end{array}$ & Origin & $\begin{array}{l}\text { Disease reaction } y / \\
\text { reference }\end{array}$ \\
\hline Bunsi & Navy & II & MI & R Schwartz et al., 1987 \\
\hline$C-20$ & Navy & II & MI & R Kelly et al., 1984 \\
\hline D76125 & Navy & I & Private & S Grafton, $1987^{x}$ \\
\hline Upland & Navy & I & Private & S Venette, 1990 \\
\hline Sierra & Pinto & II & MI & Unknown \\
\hline Topaz & Pinto & IIIa & Private & Unknown \\
\hline CO81-12034 & Pinto & III & $\mathrm{CO}$ & Unknown \\
\hline UI-114 & Pinto & III & ID & S Schwartz et al., 1987 \\
\hline NY 5403 & Snap & I & NY & $\mathrm{R}$ Venette, 1990 \\
\hline NY 5262 & Snap & I & NY & R Dickson, $1987^{\mathrm{x}}$ \\
\hline NY 5394 & Snap & I & NY & R Dickson, $1987^{x}$ \\
\hline GN-WM-85-55 & $\mathrm{GN}^{\mathrm{w}}$ & III & NE & $\mathrm{R}$ Venette, 1990 \\
\hline Harris & GN & III & $\mathrm{NE}$ & S Venette, 1990 \\
\hline PI 169787 & Brown & I & USDA & R Schwartz et al., 1987 \\
\hline PI 287536 & Black & III & USDA & Unknown \\
\hline
\end{tabular}

${ }^{\mathrm{z}}$ Growth habit: I = upright determinate, II = upright indeterminate, III = prostrate indeterminate, and IIIa = semiupright indeterminate (Singh, 1982).

y Known disease reaction: $\mathrm{R}=$ partial resistance; $\mathrm{S}=$ susceptible.

xPersonal communication.

${ }^{\mathrm{w}} \mathrm{GN}=$ great northern market class of bean.

etitions were obtained and pooled because they were homogeneous (Steel and Torrie, 1980).

\section{Results and Discussion}

28-day assay of isolate virulence

No significant $(P>0.05)$ isolate effect for LL was observed, Suggesting similar virulence among the isolates tested (Table 1).
Each isolate successfully determined PPR or 'UI-1 14' and 'Bunsi'; therefore, one isolate could be used to screen dry bean genotypes used in this study.

Heterogeneity for virulence within an isolate probably contributed to the significant $(P<0.05)$ isolate $\times$ repetition interaction for LL. Willets and Wong (1971) observed anastomoses among hyphae involved in formation of sclerotia initials in culture. This finding and the finddings of Maxwell et al. (1970) that 
some hyphal cells contain many nuclei suggest that sclerotia might contain heterokaryotic mycelium upon myceliogenic germination. If this supposition is true, then an isolate comprised of sclerotia formed from heterokaryotic mycelium in culture could be heterogeneous for virulence or other traits. Morrall et al. (1971) observed differences in virulence for isolates initiated from individual ascospores from a common apothecium. Differential response of isolates to slight changes in environment because they differed for genes for stability in performance over environments also may have contributed to the interaction.

LL difference between 'UI-114' and 'Bunsi' was greater in Repetition 2 than in 1 and probably led to the significant $(\mathrm{P}<$ $0.05)$ genotype $\times$ repetition interaction observed. Greater disease pressure was noted in Repetition 2 than in 1. Perhaps the environment of Repetition 2 favored greater expression of isolate virulence. Reisolation of isolates from infected plans before Repetition 2 may also have increased virulence.

\section{8-day assay of bean genotype resistance}

Genotype $\times$ isolate interaction for LL was not significant $(P>0.05)$ (Table 3). Nelson et al. (1991), using a similar assay with soybean, did not observe a significant genotype $\times$ isolate interaction, nor have other researchers in similar studies with S. sclerotiorum (Morrall et al., 1971; Tores and Moreno,
1987). Their results, together with ours, indicate there is no host-pathogen specificity.

An isolate $\times$ repetition interaction $(P<0.05)$ for LL (Table 3 ) occurred because isolate ND16 was less virulent in Repetition 2 than in 1. Slight changes in environment and heterogeneity for virulence among sclerotia of the isolate may have contributed to the reduced virulence of ND16 in Repetition 2.

A genotype effect $(P<0.05)$ for LL was observed, and separation of genotype LL means (Table 3 ) agreed with known disease reactions (Table 2). The LLs of partially resistant 'Bunsi' and ' $C-20$ ' were significantly lower $(P<0.05)$ than those of susceptible 'Upland' and D76125.

The genotype $\times$ run interaction $(P<0.05)$ was caused by increased LL differences between bean genotypes in Repetition 1 vs. 2 and. changes of genotype rank. The LL rankings of navy and pinto genotypes were similar each repetition, indicating that the 28-day assay reliably determined PPR in these market classes. To further investigate reliability of the 28-day assay, it was repeated, using two repetitions, isolate ND26, $4.5 \times 5.5 \times$ $3.5-\mathrm{cm}$ potting containers, and a combination of seven navy and pinto bean genotypes and one snap bean. No genotype $x$ repetition interaction $(P>0.05)$ for $L L$ and a genotype ranking for LL similar to that of the previous assay confirmed reliability of the 28-day assay.

Table 3. LL and infected stem volume means ${ }^{z}$ of excised stems from 11- and 28-day-old plants (11- and 28-day assays) of bean genotypes inoculated with one and three isolates of Sclerotinia sclerotiorum, respectively.

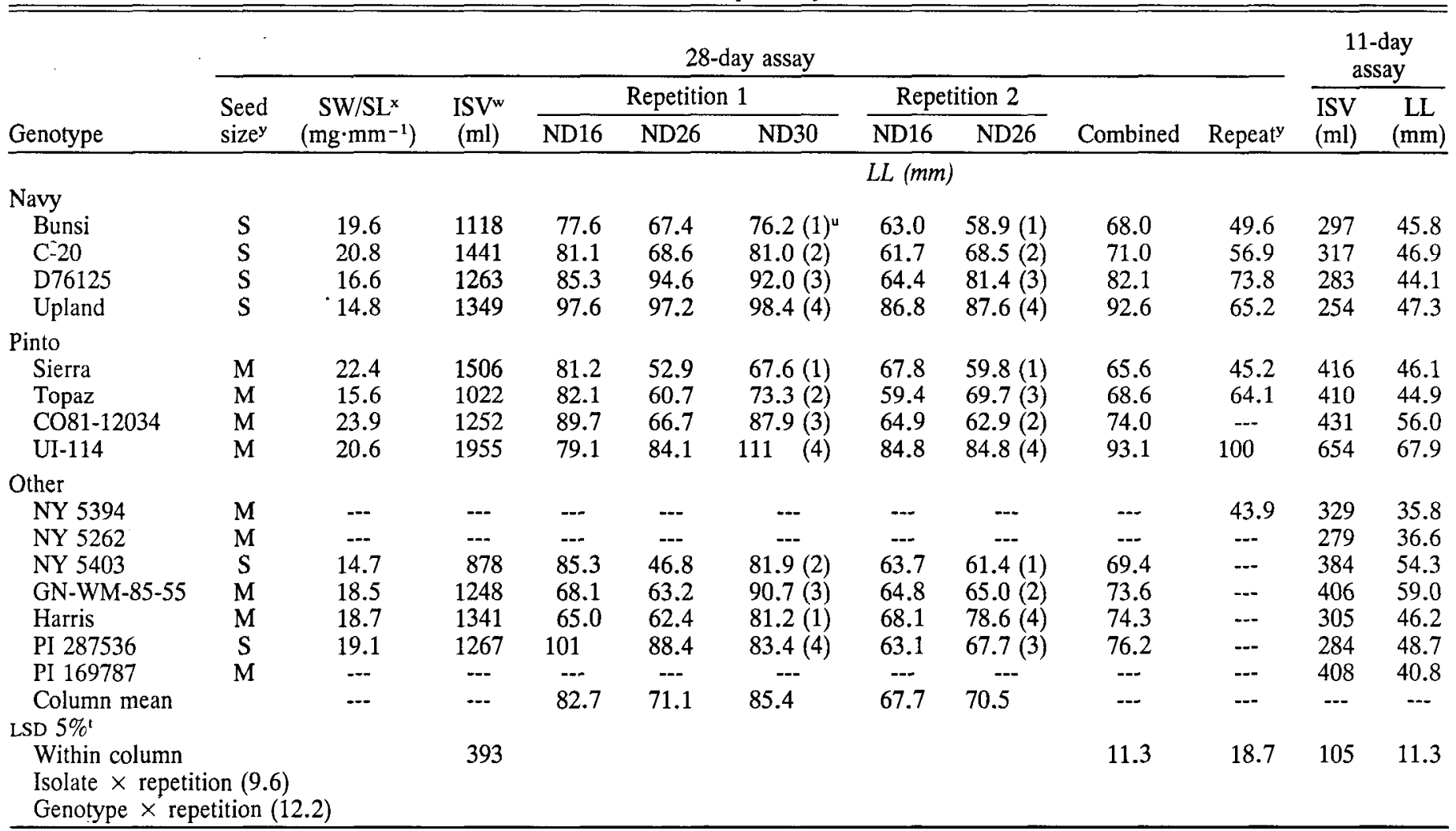

${ }^{2}$ LL means for the 28-day assay are based on eight replicates, and LL and ISV means for the 11-day assay represent a combination of five repetitions with five replications per repetition.

${ }^{y}$ Seed size: $\mathrm{M}=$ medium $(>28 \mathrm{~g} / 100$ seed) and $\mathrm{S}=\operatorname{small}(<28 \mathrm{~g} / 100$ seed).

${ }^{x, w}$ Stem weight divided by stem length (SW/SL) and infected stem volume (ISV) means of the 28-day assay were obtained across two isolates and four replicates from Repetition 2.

'A repeat of the 28-day assay with 15 replicates combined across two repetitions, using ND26.

'Ranking of the means combined across isolates.

LSDS were based on smallest $\mathrm{N}$. 


\section{1-day assay of bean genotype resistance}

The inoculation of excised stems from 1 1-day-old plants was evaluated for its ability to determine PPR because it required less labor, incubation, and space compared with the 28-day assay. The 11-day assay appeared reliable because no genotype $\times$ repetition interaction $(P>0.05)$ and a significant $(P<0.05)$ genotype effect for LL were observed (Table 3). Mean differences of the LL trait were detected only among medium-seeded genotypes, however, perhaps because excised stem lengths of small-seeded genotypes were 5 to $10 \mathrm{~cm}$ shorter than those of medium-seeded genotypes. Lesions advanced the entire stem length of shorter excised stems before LL was measured. Evaluation of LL after 3 days of incubation alleviated the lesion advancement problem somewhat but was not useful in differentiating among LL means of small-seeded genotypes. The LL means of medium-seeded genotypes paralleled those estimates from the 28-day assays, except that 'Harris' had a lower LL mean in the 11-day assay.

\section{Stem size and lesion characteristics}

There was concern that thick stems would slow lesion progress more than thin stems, creating a bias toward thicker-stemmed genotypes. One might use an estimate of stem size (stem weight divided by stem length) as a covariate to adjust genotype LL means to remove the bias, if present. Regression analyses showed that there was no significant $(P>0.05)$ linear relationship between LL and stem weight divided by stem length in either the 11- or 28-day assay. Thus, stem weight divided by stem length was not useful as a covariate.

Researchers have used other means to measure physiological resistance of stem tissue to S. sclerotiorium without bias. Tores and Moreno (1987) used lesion perimeter or stem diameter to calculate infected stem volume, and Sedun et al. (1989) used a lesion expansion rate to estimate PPR of stem tissue. We tried to estimate infected stem volume with stem diameter and displacement of water in graduated cylinders, but measurement was too difficult. Instead, we estimated infected stem volume.

In the 28-day assay, genotype ranking for infected stem volume differed markedly from the genotype ranking for LL, and in the 1 1-day assay genotype ranking changed between repetitions, causing a significant $(P<0.05)$ genotype $\times$ repetition interaction for infected stem volume (Table 3 ). Our estimate for infected stem volume does not appear to determine PPR.

Our finding that lesions progressed independently of stem thickness and volume was similar to the findings of Hunter et al. (1982). Lumsden's (1979) review of hyphal growth within bean tissue provides an explanation. He noted that subcuticular hyphae progressed rapidly up the hypocotyl and probably were vital to rapid lesion advancement. The subcuticular hyphae may allow lesion advancement to occur independently of stem diameter.

Characteristics of lesions varied among genotypes. With resistant bean genotypes, when a lesion reached a node, its advancement was retarded and sometimes stopped altogether. Perhaps interruption of the subcuticular region at a node retards lesion growth by slowing advancement of the subcuticular hyphae. The influence internode length has on LL warrants further investigation; until then, only LL comparisons between genotypes of similar growth habit (Singh, 1982) and seed size are recommended.

Short lesions of resistant genotypes generally had reddishbrown borders. Schwartz et al. (1978) also observed this border phenomenon in dry bean. Similarly, Boland and Hall (1986) and Cline and Jacobsen (1983) observed lesions with reddishbrown borders on moderately resistant soybean. Perhaps the reddish-brown pigmentation is due to phytoalexin accumulation. Sutton and Deverall (1984) measured an accumulation of phytoalexin in dry bean hypocotyls that had lesions of limited size. Although these observations of lesion characteristics were not consistent over all replicates and repetitions, they do suggest that different mechanisms of physiological resistance may exist in stem tissue.

\section{Field trials}

Partial field resistance of 13 dry bean genotypes to white mold was determined by a DII obtained in field trials at Oakes (Table 4). Initial. symptoms of white mold appeared, scattered throughout each field trial, at the R4 growth stage (Fernandez and Gepts, 1984.). Equally severe white mold for 'UI-114' in every replication and field trial, during rating 3 to 4 weeks later, indicated disease pressure was evenly distributed.

The DII of this study was developed to allow greater separation between bean genotypes of similar resistance. Compared with the DII, the rating score (0 to 5) is easy to obtain and it can adequately separate bean genotypes that differ greatly for resistance. In the breeding program, when evaluating advanced bean breeding lines for field resistance to white mold we use a visual score alone.

No genotype $x$ trial interaction $(P>0.05)$ and the high overall DII of Trial 3 relative to Trials 1 and 2 indicated that expression of avoidance was probably reduced by our methods (Table 4). Therefore, expression of PPR in the field trials was likely and explains the significant pooled correlation $(r=0.68$; $P<0.02$ ) obtained between DII and LL means (28-day assay), because LL also indicates PPR. Lesion length means from the 11-day assay did not correlate significantly $(r=0.18 ; P>$ 0.05 ) to DII means because LL means among the small-seeded genotypes were undifferentiated (Table 3 ). A significant pooled correlation $(r=0.89 ; \mathrm{P}<0.02)$ between LL means from this study (28-day assay) and callus weight means obtained in another study (Miklas et al., 1992), supports our view that LL values, in part, indicate PPR resistance. DII did not correlate significantly $(P>0.05)$ with infected stem volume from 11 - or 28 -day assays, $r=0.24$ and 0.39 , respectively.

DII of most bean genotypes (Table 4) agreed with known disease reactions listed in Table 2, except 'Harris', which had a low DII. The DII of bean genotypes of unknown disease reaction, 'Topaz' and C081-12034, and 'Sierra' and PI 287536, indicated low and intermediate levels of field resistance, respectively. Discrepancies existed between DII and LL means of some bean genotypes (Table 3). Lesion length of PI 287536 and GN-WM-85-55 (28-day assay) indicated susceptibility, whereas their rankings for DII indicated some field resistance.

The partial resistance of 'Bunsi', when compared with the other bean genotypes, was greater if measured by DII than LL (28-day assay). This discrepancy is large enough to suggest that 'Bunsi' may have an important mechanism of physiological resistance that is not expressed in the 28-day assay. 'Bunsi' characteristically retains a green stem at maturity, which suggests that its physiological resistance mechanisms may operate for a longer period than those of other genotypes. We have observed that other cultivars retaining a green stem at maturity also appear to express greater resistance to white mold in the field than others.

Generally, late-maturing genotypes had greater field resis- 
Table 4. DII means of 13 bean genotypes evaluated for field resistance to white mold at Oakes, N.D., in 1988 and 1989.

\begin{tabular}{|c|c|c|c|c|c|c|c|}
\hline \multirow[b]{2}{*}{ Genotype } & & \multirow[b]{2}{*}{ Maturity $^{\mathbf{z}}$} & \multicolumn{3}{|c|}{ Field trials } & \multirow[b]{2}{*}{ Combined } & \multirow[b]{2}{*}{$\mathrm{N}^{\mathrm{y}}$} \\
\hline & & & 1 & 2 & 3 & & \\
\hline & & ' & & & & & \\
\hline \multicolumn{8}{|l|}{ Navy } \\
\hline Bunsi & & L & 3.9 & 4.6 & 4.0 & 4.4 & 10 \\
\hline C-20 & & $\mathrm{L}$ & 5.6 & 9.8 & 11.9 & 9.0 & 10 \\
\hline Upland & & I & 15.5 & 20.4 & 19.3 & 18.4 & 10 \\
\hline D76125 & & $E$ & 17.5 & --- & -- & 20.4 & 4 \\
\hline \multicolumn{8}{|l|}{ Pinto } \\
\hline Sierra & $\because$ & $\mathbf{L}$ & 7.2 & 11.6 & 13.8 & 10.8 & 10 \\
\hline Topaz & & $\bar{E}$ & 9.0 & 15.2 & 18.6 & 14.0 & 10 \\
\hline CO8112034 & & $E$ & 9.1 & 17.6 & 14.4 & 13.5 & 10 \\
\hline UI-114 & & I & 15.5 & 17.4 & 20.9 & 18.0 & 10 \\
\hline \multicolumn{8}{|l|}{ Other } \\
\hline NY 5403 & & VL & 5.6 & 10.1 & 10.4 & 8.6 & $\cdots 10$ \\
\hline GN-WM-85-55 & & $\mathrm{L}$ & 7.3 & 6.2 & 10.3 & 8.2 & 10 \\
\hline Harris & & $\mathrm{L}$ & 11.1 & 10.6 & 16.8 & 12.9 & 10 \\
\hline PI 169787 & & $\bar{I}$ & - & 9.5 & 12.1 & 9.4 & 4 \\
\hline PI 287536 & & I & 6.3 & 11.7 & 12.6 & 10.2 & 9 \\
\hline \multirow[t]{5}{*}{$\operatorname{LSD} 5 \%^{x}$} & & & & & & 3.12 & $10-10$ \\
\hline & & & & & & 3.20 & $10-9$ \\
\hline & & & & & & 4.12 & $10-4$ \\
\hline & & & & & & 4.19 & $9-4$ \\
\hline & & & & & & 5.15 & $4-4$ \\
\hline
\end{tabular}

${ }^{2}$ Relative maturity: $\mathrm{E}=$ early, $\mathrm{I}=$ intermediate, $\mathrm{L}=$ late, and $\mathrm{VL}=$ very late.

y Number of observations in the combined means.

${ }^{\mathrm{x}} \mathrm{LSD}$ for comparing combined means, of specific N.

tance, as indicated by lower DII, than early maturing genotypes. Conversely, Nuland and Carlson (1989) showed that early maturing genotypes displayed greater resistance in field trials. This discrepancy may result from an early and late onset of disease in our field trials and those of Nuland and Carlson (1989), respectively. The effects, if any, that plant maturity may have on physiological mechanisms of field resistance are unknown.

Lesions with reddish-brown borders often were observed on bean genotypes with relatively high field resistance, similar to bean genotypes with relatively high physiological resistance observed in the 11- and 28-day assays. In addition, lesions <5 $\mathrm{mm}^{2}$ in size, with or without reddish-brown borders and consisting of necrotic tissue (pale flecks), most often occurred on genotypes with the greater field resistance. The occurrence of reddish-brown borders and small lesions predominantly on genotypes with relatively high field resistance may be associated with heritable mechanisms of plant defense. Boland and Hall (1986) had a similar notion, based on observations in soybean.

The 28-day assay is not useful for selecting individual plants for PPR because it is a destructive test, but it is suitable for screening cultivars, plant introductions, and advanced breeding lines, which can be replicated easily. Replication is necessary for precise measurement of PPR, because PPR appears to be quantitatively inherited (Fuller et al., 1984).

\section{Literature Cited}

Boland, G.J. and R. Hall. 1986. Growthroom evaluation of soybean cultivars for resistance to Sclerotinia sclerotiorum. Can. J. Plant Sci. 66:559-564.

Chun, D., L.B. Kao, and J.L. Lockwood. 1987. Laboratory and field assessment of resistance in soybeans to stem rot caused by Sclerotinia sclerotiorum. Plant Dis. 71:811-815.
Cline, M.N. and B.J. Jacobsen. 1983. Methods for evaluating soybean cultivars for resistance to Sclerotinia sclerotiorum. Plant Dis. 67:784786.

Cochran, W.G. and G.M. Cox. 1957. Experimental designs. 2nd ed. Wiley, New York.

Coyne, D. P., J.R. Steadman, and H.F. Schwartz. 1977. Reaction of Phaseolus dry bean germplasm to Sclerotinia sclerotiorum. Plant Dis. Rptr. 61:226-320.

Dickson, M.H., J.E. Hunter, M.A. Boettger, and J.A. Cigna. 1982. Selection for resistance in Phaseolus vulgaris L. to white mold disease caused by Sclerotinia sclerotiorum (Lib.) deBary. J. Amer. Soc. Hort. Sci. 107:231-234.

Fernandez, F. and P. Gepts. 1984. A scale of developmental stages of the bean plant Phaseolus vulgaris. Mich. Dry Bean Dig. 9(1):1415.

Fuller, P.A., D.P. Coyne, and J.R. Steadman. 1984. Inheritance of resistance to white mold disease in a diallel cross of dry beans. Crop Sci. 24:929-933.

Gomes, F.P. and R.F. Guimaraes. 1957. Joint analysis of experiments in complete randomized blocks with some common treatments. Biometrics 14:521-526.

Hunter, J.E., M.H. Dickson, M.A. Boettger, and J.A. Cigna. 1982. Evaluation of plant introductions of Phaseolus spp. for resistance to white mold. Plant Dis. 66:320-322.

Hunter, J. E., M.H. Dickson, and J.A. Cigna. 1981. Limited-term inoculation: a method to screen bean plants for partial resistance to white mold. Plant Dis. 65:414-417.

Kelly, J. D., M.W. Adams, A.W. Saettler, G.L. Hosfield, and A. Ghaderi. 1984. Registration of C-20 navy bean. Crop Sci. 24:822.

Lumsden, R.D. 1979. Histology and physiology of pathogenesis in plant diseases caused by Sclerotinia species. Phytopathology 69:890896.

Lyons, M. E., M.H. Dickson, and J.E. Hunter. 1987. Recurrent selection for resistance to white mold in Phaseolus species. J. Amer. Soc. Hort. Sci. 112:149-152. 
Maxwell, D. P., P.H. Williams, and M.D. Maxwell. 1970. Microbodies and lipid bodies in the hyphal tips of Sclerotinia sclerotiorum. Can J. Bet. 48:1689-1691.

Miklas, P.N., K.F. Grafton, G.A. Secor, and P.E. McClean. 1992. Use of pathogen filtrate to differentiate partial physiological resistance of dry bean to white mold disease. Crop Sci. (In press.)

Morrall, R. A. A., L.J. Duczek, and J.W. Sheard. 1971. Variations and correlations within and between morphology, pathogenicity, and pectolytic enzyme activity in Sclerotinia from Saskatchewan. Can. J. Bet. 50:767-786.

Nelson, B.D. 1985. Inoculum preparation of Sclerotinia sclerotiorum for infection of sunflower and other hosts. Phytopathology 75:1333. (Abstr.)

Nelson, B. D., T.C. Helms, and I. Kural. 1991. Effects of temperature and pathogen isolate on laboratory screening of soybean for resistance to Sclerotinia sclerotiorum. Can J. Plant Sci. 71:347-352.

Nuland, D. and C. Carlson. 1989. White mold variety trial results 1988. Annu. Rpt. Bean Improv. Coop. 32:111-112.

Schwartz, H. F., D.H. Casciano, J.A. Asenga, and D.R. Wood. 1987. Measurement of white mold effects upon dry beans with genetic resistance or upright plant architecture. Crop Sci. 27:699-702.

Schwartz, H. F., J.R. Steadman, and D.P. Coyne. 1978. Influence of Phaseolus vulgaris blossoming characteristics and canopy structure upon reaction to Sclerotinia sclerotiorum. 1978. Phytopathology 68:465-470.

Sedun, F. S.. G. Seguin-Swartz. and G.F.W. Rakow. 1989. Genetic variation in reacti\&r to Sclerotinia stem rot in Brassica species. Can. J. Plant Sci. 69:229-232.

Singh, S.P. 1982. A key for identification of different growth habits of Phaseolus vulgaris L. Annu. Rpt. Bean Improv. Coop. 25:9295.

Steadman, J.R. 1979. Control of plant diseases caused by Sclerotinia species. Phytopathology. 69:904-907.

Steel, R.G.D. and J.H. Torrie. 1980. Principles and procedures of statistics. McGraw-Hill, New York.

Sutton, D.C. and B.J. Deverall. 1984. Phytoalexin accumulation during infection of bean and soybean by ascospores and mycelium of Sclerotinia sclerotiorum. Plant Pathol. 33:377-383.

Tores, J.A. and R. Moreno. 1987. Lesion development factors following inoculation of Sclerotinia scleroliorum mycelium to eggplant, tomato, and french bean. Phytoparasitica 15:325-333.

Venette, J.R. 1990. An exponential inoculator for studies of white mold on beans. Annu. Rpt. Bean Improv. Coop. 33:4-5.

Willets, H.J. and A.L. Wong. 1971. Ontogenetic diversity of sclerotia of Sclerotinia sclerotiorum and related species. Trans Br. Mycol. Soc. 57:515-524. 